\title{
Essential Oil Extracted from Wood of Phoebe bournei (Hemsl.) Yang: Chemical Constituents, Antitumor, Antibacterial, and Hypoglycemic Activities
}

\author{
Wen Ding, ${ }^{\text {a,b }}$ Liping Ning,, a,b,* Shaoxuan Wei, ${ }^{\mathrm{c}}$ Huizi Xing, ${ }^{\mathrm{a}, \mathrm{b}}$ Zhiting Wei, ${ }^{\mathrm{a}, \mathrm{b}}$ and \\ Yingjian $\mathrm{Li}^{\mathrm{d}}$
}

The essential oil was extracted from the wood of Phoebe bournei (Hemsl.) Yang by a hydrothermal method and then analyzed by gas chromatography-mass spectrometry. The wood oil was comprised mainly of $\alpha$-copaene $(5.44 \%)$, a-muurolene $(7.32 \%)$, $\delta$-cadinene $(11.44 \%)$, and 1s-calamenene (5.18\%). $P$. bournei wood essential oil exhibited significant antifungal properties against Candida albicans, Trichophyton rubrum, Epidermophyton floccosum, and Microsporum gypseum, and it showed good potential antitumor activity against leukemia cell lines. Although $P$. bournei (Hemsl.) Yang wood essential oil exhibited weaker activity against the four tested bacteria, it had some effect on promoting glucose uptake by adipocytes.

Keywords: Essential oil; Chemical constituents; Antitumor activity; Antifungal activity; Hypoglycemic activity

Contact information: a: College of Forestry, Sichuan Agricultural University, Chengdu 611130, PR China; $b$ : Key Laboratory of Wood Industry and Furniture Engineering, Sichuan Agricultural University, Chengdu 611130, PR China; c: Guangxi University of Chinese medicine, PR China; d: Guangxi University, PR China; * Corresponding author:247894463@qq.com

\section{INTRODUCTION}

Phoebe bournei (Hemsl.) Yang, an evergreen tree in the Lauraceae family, is a world-renowned precious tree species used for timber production and landscaping and a national second-class protected plant (Liu et al. 2014b). Historically, P. bournei, C. camphora (L.) Presl, C. ovata G. Don, and C. glavca (Thunb.) Oerst were called the four famous woods (Chen and Xie 2014). P. bournei is dry and straight, with a magnificent tree crown, vertical wood texture, fine structure, no warping and deformation, and resistance to insects and corrosion, making it a good material for high-grade buildings and fine furniture (Gao et al. 2016). It is also the main tree species of Phoebe jinsinan, one of the ancient exclusive royal woods, known as "Emperor Wood" (He et al. 2013).

Due to its enormous economic value and wide range of uses, P. bournei has suffered severe damage (Liu et al. 2014a). Currently, it is only sporadically distributed in mountainous, evergreen broad-leaved forests 200 to 1000 meters above sea level in Zhejiang, Fujian, Guangxi, and Guizhou provinces of China (Zhang and Iwatsuki 2013). Plant essential oil is a secondary metabolite of plants and is widely used in pest control, cosmetics, food, medicine and other fields (Bedini et al. 2016; Perdones et al. 2016; Salahfatnassi et al. 2016). Studies have shown that Phoebe zhennan plays an important role in the development of natural aromatic resources. Phoebe zhennan seed oil can be used as raw material for cosmetics production (Ren et al. 1990) and its wood essential oil has certain bactericidal and antitumor activity. According to the ancient Chinese medical book 
"Compendium of Materia Medica" "Taiping Shenghui Fang", Nanmu is used as a medicine, which can treat stomach diseases, cholera, tendons, otitis media (otitis), athlete's foot and other diseases. At present, studies on $P$. bournei are limited to biological characteristics (Zhou et al. 2005; Zhang et al. 2012), wood properties (Jiang et al. 2008), nursery techniques (Huang et al. 2016; Zhang et al. 2016a, b), and artificial forest management (Shao et al. 2014; Huang et al. 2017; Yu and Chen 2017). Research on the chemical constituents and biological activity of the essential oil and other aspects had not been carried out yet.

The wood structures of Phoebe Ness and its closely related species are very similar. It is difficult to identify the species accurately by traditional methods. However, there is a high demand for the identification of the species of the jinsinan wood in the timber market (Yang et al. 2018). Also there is a need for reliable forensic identification of the species. Studies have shown that there are differences in the chemical composition of the P. bournei wood and other species in the same genus (Ding et al. 2017b; Wang et al. 2017; Xue and Zhao 2017). This study tested and analyzed the chemical composition of $P$. bournei essential oil, in order to provide a reference for the identification of $P$. bournei, regulate the trade of jinsinan wood, and promote the prosperity and development of the market.

\section{EXPERIMENTAL}

\section{Extraction of Essential Oil}

The experimental raw material P. bournei was provided by Yiming Wood, Rongshui County, Guangxi Province. The age of the tree was 1700 years. Wood samples were collected at $1.3 \mathrm{~m}$ above the ground. The moisture content of the wood was $16.8 \%$.

The essential oil was extracted from the wood of $P$. bournei by a hydrothermal method. First, a crushed sample of $P$. bournei weighing $200 \pm 0.01 \mathrm{~g}$ was accurately measured using an analytical balance and added to a $2000 \mathrm{~mL}$ round-bottomed flask. Next, distilled water $(1200 \mathrm{~mL})$ was introduced, and several glass beads were added to prevent bumping. The extraction apparatus was assembled and heated for $5 \mathrm{~h}$ (until the volume of the essential oil remained constant). After settling for $0.5 \mathrm{~h}$, the volume of the extract was recorded, with three replications.

\section{Instrumentation}

The instruments used were an Agilent 7890A-5975C gas chromatography-mass spectrometry (GC-MS) system (Hercules, CA, USA), an Agilent 7890A gas chromatography (GC) system, a steam distiller supplied by Shuniu Glassware Co., Ltd (Chengdu, China), a Sartorius CP224S analytical balance (Sartorius, Göttingen, Germany), and a multifunctional enzyme marker Multiskan FC (Thermo, Waltham, MA, USA).

\section{Gas Chromatography Analysis}

An Agilent HP-5 chromatography column $(30 \mathrm{~m} \times 0.25 \mathrm{~mm} \times 0.50 \mu \mathrm{m})$ was used. The sample injection volume was $1 \mu \mathrm{L}$, the split ratio was 50:1, the detector temperature was $250^{\circ} \mathrm{C}$, and the carrier gas used was ultra-pure helium. The oven temperature program was as follows: $120{ }^{\circ} \mathrm{C}$ for $3 \mathrm{~min}$, increased to $140{ }^{\circ} \mathrm{C}$ at $5{ }^{\circ} \mathrm{C} / \mathrm{min}$ over $5 \mathrm{~min}$, then increased to $160{ }^{\circ} \mathrm{C}$ at $2{ }^{\circ} \mathrm{C} / \mathrm{min}$ over $10 \mathrm{~min}$. The flow rate was $1 \mathrm{~mL} / \mathrm{min}$, and the machine was equipped with a flame ionization detector. The components in the essential oil were identified by retention indices that were determined with $\mathrm{C} 7-\mathrm{C} 20$ alkane standards as the 
reference and that were confirmed by GC-MS.

\section{Gas Chromatography-Mass Spectrometry Analysis}

The gas chromatography conditions are detailed above.

The ion source for the mass spectrography was electron ionization. The ionization energy was $70 \mathrm{eV}$, the auxiliary heating zone was $280{ }^{\circ} \mathrm{C}$, the ion source was $230{ }^{\circ} \mathrm{C}$, and the quadrupole temperature was $150{ }^{\circ} \mathrm{C}$. The data acquisition mode was set to full scan, with a mass scanning range of 50 to $550 \mathrm{~m} / \mathrm{z}$ and a solvent delay of $3 \mathrm{~min}$. The GC-MS spectra were analyzed via a computer-based automatic search, the automated and manual analyses of a mass spectral library (NIST), and a literature search to identify each component. Finally, the relative contents of each constituent were calculated using the peak area normalization method.

\section{Antibacterial Assay of the Extracted Essential Oil}

Escherichia coli ATCC25922, Staphylococcus aureus subsp. aureus ATCC29213, Salmonella enterica subsp. enterica ATCC14028, Pseudomonas aeruginosa ATCC27853, Candida albicans, Epidermophyton floccosum, Trichophyton rubrum, and Pseudomonas aeruginosa were obtained from the China General Microbiological Culture Collection Center (CGMCC). Streptomycin was obtained from HyClone Co. (Los Angeles, USA), and penicillin $\mathrm{G}$ sodium was obtained from Biosharp Co. (Hefei, China). Terbinafine, amphotericin B, and DMSO were obtained from Sigma (San Francisco, CA, USA). Chloramphenicol was purchased from Scientific Research Special (San Francisco, CA, USA).

First, the samples were diluted to specific concentrations and added to the individual wells of a 96-well microplate. Next, the bacterial solutions were added and diluted to obtain a final concentration of $5 \times 10^{5} \mathrm{CFU} / \mathrm{mL}$, and then cultured for $24 \mathrm{~h}$ at 37 ${ }^{\circ} \mathrm{C}$. A microplate photometer was used to measure the optical density (OD) below $625 \mathrm{~nm}$. Each treatment was the same as the three controls, and the mean value was taken. Control cultures, blank media, bacterial cultures, and penicillin-streptomycin and penicillin $G$ sodium-positive controls were prepared. Inhibition rates were calculated based on Eq. 1 (NCCLS 2002a,b).

Inhibition rate $=(1-\mathrm{OD}$ value of sample/OD value of control well $) \times 100 \%$

\section{Antifungal Assay of the Extracted Essential Oil}

For the antifungal experiment, the samples to be tested were diluted by adding fungal liquid to each well of the 96-well plate. The final concentration of Candida albicans was $1 \times 10^{5} \mathrm{CFU} / \mathrm{mL}$. Epidermophyton floccosum and Trichophyton rubrum were incubated at $37{ }^{\circ} \mathrm{C}$ for $24 \mathrm{~h}$.. The final concentration of Plasmodium sp. was $5 \times 10^{5}$ $\mathrm{CFU} / \mathrm{mL}$, incubated at $25{ }^{\circ} \mathrm{C}$ for 5 days, and the OD value at $625 \mathrm{~nm}$ was measured with a microplate reader. The experiment included a blank control medium, Candida albicans, Epidermophyton floccosum, Trichophyton rubrum, and the Pseudomonas aeruginosa control, along with the amphotericin B and terbinafine positive drug controls. The inhibition rates were calculated as shown in Eq. 1 (Liu 2003).

\section{Antitumor Assay of the Extracted Essential Oil}

The leukemia cell line HL-60, the lung cancer cell line A549, the hepatoma cell line SMMC-7721, the breast cancer cell line MCF-7, and the colon carcinoma cell line 
SW480 were used. All cell lines were stored in the Kunming Institute of Botany. Cisplatin (DDP) and Taxol were also provided by the institute. All reagents were of analytical grade. Dulbecco's modified Eagle medium (DMEM) culture medium containing 10\% fetal bovine serum was used to formulate a single-cell suspension culture. Approximately 3000 to 15000 cells per well were seeded into the 96-well plates, with a volume of $100 \mu \mathrm{L}$ in each well. Adherent cells were cultured 12 to $24 \mathrm{~h}$ in advance. Next, $20 \mu \mathrm{L}$ of the supernatant from the samples was removed and dissolved in dimethyl sulfoxide. The essential oil samples were rescreened using five concentration gradients: 100, 20, 4, 0.8, and $0.16 \mu \mathrm{g} / \mathrm{mL}$. Each well had a final volume of $200 \mu \mathrm{L}$, each treatment was performed in triplicate, and the mean value was taken. The samples were incubated at $37{ }^{\circ} \mathrm{C}$ for $48 \mathrm{~h}$. After the incubation period, the media from the adherent cell cultures were discarded, and a solution of 3-(4,5-dimethylthiazol-2-yl)-5-(3-carboxymethoxyphenyl)-2-(4-sulfophenyl) -2H-tetrazolium (MTS) $(20 \mu \mathrm{L})$ and culture medium $(100 \mu \mathrm{L})$ were added to each well. For the cultured suspension cells, $100 \mu \mathrm{L}$ of the supernatant was discarded from each well; then, MTS solution $(20 \mu \mathrm{L})$ was added to each well. The cultures were further incubated for another 2 to $4 \mathrm{~h}$. After the reactions had reached completion, the microplate photometer was employed to measure the OD value below $492 \mathrm{~nm}$. DDP and Taxol were used as positive controls for each measurement. The cell growth curves were plotted with the concentration and cell viability on the $\mathrm{x}$ - and $\mathrm{y}$-axes, respectively. The two-point ReedMuench method was employed to calculate the half-maximal inhibitory concentration (IC50) values of the compounds ( $\mathrm{Li}$ et al. 2017) were calculated as shown in Eq. 1.

\section{Hypoglycemic Assay of the Extracted Essential Oil}

3T3-L1 adipocytes (adipocyte lines were preserved in Kunming Institute of Botany), insulin, berberine, and MTS were provided by Kunming Institute of Botany (Kunming, China). After 3T3-L1 cells were induced to differentiate into adipocytes, the cells were digested and seeded in 96-well plates and cultured overnight. After the cells were washed once with a low-glucose medium (glucose concentration $1800 \mathrm{mg} / \mathrm{L}$ ), $200 \mu \mathrm{L}$ of low-sugar medium containing different drugs was added. The control group was incubated with DMSO and $100 \mu \mathrm{M}$ insulin and berberine, respectively, and the test sample group was incubated at a final concentration of $40 \mu \mathrm{g} / \mathrm{mL}$. Three replicate wells were used per sample.

After incubation for $24 \mathrm{~h}, 10 \mu \mathrm{L}$ of cell culture medium was aspirated, and the glucose concentration in the culture fluid was measured by the glucose oxidase-peroxidase method. At the same time, $20 \mu \mathrm{L}$ of MTS was added to the cell rest medium and incubated at $37{ }^{\circ} \mathrm{C}$ for $2 \mathrm{~h}$. The absorbance at $492 \mathrm{~nm}$ was used to judge whether the compound was toxic to adipocytes. The glucose concentration and glucose consumption rate were calculated by Eqs. 2 and 3, respectively (Zhang et al. 2011).

Glucose concentration $(\mathrm{mmol} / \mathrm{L})=\frac{\text { sample absorbance }}{\text { standard absorbance }} \times$ calibrator concentration

Glucose consumption $(\%)=\frac{\text { iniitial concentration-experimental concentration }}{\text { initial concentration }} \times 100$ 


\section{RESULTS AND DISCUSSION}

\section{Analysis of the Main Chemical Constituents of $\boldsymbol{P}$. bournei Wood}

Under the experimental conditions, the yield of essential oil from the wood of $P$. Bournei was $0.9 \mathrm{~mL} / 100 \mathrm{~g}$. By GC-MS analysis, a total of 46 components were isolated from the wood samples. A total of 34 compounds were identified, and the sum of the relative contents accounted for $88.38 \%$ of the total sample content. The GC-MS spectra were analyzed via a computer-based automatic search, the automated and manual analyses of a mass spectral library (NIST), and a literature search to identify each component. Finally, the relative contents of each constituent were calculated using the peak area normalization method. Table 1 shows the results.

In this study, the chemical constituents of the essential oil from the P. bournei were identified, and their relative contents were measured. Under the experimental conditions, as shown in Table 1, the main constituents of the essential oil extracted from P. bournei were enol compounds. The sesquiterpene content of the wood sample was $84.46 \%$, the monoterpene content was $0.64 \%$, and the other component compounds were $3.28 \%$. The main constituents of wood oil included $\alpha$-copaene $(5.44 \%), \alpha$-muurolene $(7.32 \%), \delta$ cadinene $(11.44 \%)$, and $1 \mathrm{~s}$-calamenene $(5.18 \%)$.

The main volatile components of Phoebe wood from different production areas were basically the same, while the chemical compositions of different species of Phoebe differed greatly. The main chemical constituents of $P$. bournei wood essential oil were $\alpha$ copaene, $\alpha$-muurolene, and $\delta$-cadinene. The main chemical components of Phoebe hui Cheng ex Yang wood were 3,7-guaiadiene, calarene, and torreyol (Ding et al. 2017b). The main components of Phoebe zhennan wood oil were agaruspirol, guaiol, and $\gamma$-eudesmol (Ding et al. 2017a). It could be seen that the major components of the three were indeed very different from each other. Hence, it would be feasible to identify the Phoebe wood by chemical composition, and this is more accurate and objective than the traditional identification.

\section{Study on the Bioactivity of the Essential Oil}

Analysis of the antimicrobial effects of the essential oil extracted from the wood of $P$. bournei

The positive drugs Penicillin G Sodium and Streptomycin have an IC50 of less than $2 \mu \mathrm{g} / \mathrm{mL}$ for the four bacteria. Figure 1 shows that $P$. bournei wood oil had an inhibitory effect on the four tested bacteria; at all concentrations, $P$. bourne $i$ wood oil demonstrated the best activity against $P$. aeruginosa. Moreover, in the remaining three bacteria, when the concentration of $P$. bournei wood oil was less than $32 \mu \mathrm{g} / \mathrm{mL}$, the inhibitory effect of $P$. bournei wood oil against $S$. aureus and $S$. enteritidis was lower than that of $E$. coli. When the concentration was more than $32 \mu \mathrm{g} / \mathrm{mL}$, the inhibitory effect of $P$. bournei wood oil against $S$. aureus and $S$. enteritidis was better than that of $E$. coli.

The concentration of essential oil ranged from $8 \mu \mathrm{g} / \mathrm{mL}$ to $128 \mu \mathrm{g} / \mathrm{mL}$, and the inhibitory rates of wood essential oil from $P$. bournei on the four tested bacteria showed an increasing trend, and had the best inhibitory effect against $P$. aeruginosa. The $\mathrm{IC}_{50}$ of the essential oil to four bacteria was greater than $128 \mu \mathrm{g} / \mathrm{mL}$, indicating that the inhibition effect of $P$. bournei wood essential oil against $E$. coli ATCC25922, Staphylococcus aureus golden subspecies ATCC29213, Salmonella enterica subspecies ATCC14028, and Pseudomonas aeruginosa ATCC27853 is relatively weak, which is the same as the results of Phoebe hui and Phoebe zhennan wood essential oil (Ding et al. 2017a,b). 
Table 1. The Chemical Composition of $P$. bournei Wood Oil

\begin{tabular}{|c|c|c|c|}
\hline No. & Compound & $\mathrm{KI}$ & Area \\
\hline 1 & a-copaene & 1515 & 1.08 \\
\hline 2 & camphor & 1552 & 0.60 \\
\hline 3 & isopinocamphon & 1582 & 1.25 \\
\hline 4 & nopinone & 1618 & 1.22 \\
\hline 5 & caryophyllene & 1624 & 0.48 \\
\hline 6 & myrtenal & 1662 & 0.55 \\
\hline 7 & pinocarveol & 1685 & 2.35 \\
\hline 8 & p-menth-2-ene-1,8-diol & 1700 & 0.33 \\
\hline 9 & verbenol & 1707 & 2.18 \\
\hline 10 & a-terpineol & 1721 & 1.97 \\
\hline 11 & endo-borneol & 1728 & 0.80 \\
\hline 12 & verbenone & 1746 & 6.38 \\
\hline 13 & p-mentha-1,5-dien-8-ol & 1775 & 1.67 \\
\hline 14 & & 1786 & 0.46 \\
\hline 15 & d-cadinene & 1816 & 2.93 \\
\hline 16 & myrtenol & 1855 & 1.76 \\
\hline 17 & & 1849 & 0.56 \\
\hline 18 & calamenene & 1855 & 3.95 \\
\hline 19 & carveol & 1862 & 0.66 \\
\hline 20 & p-cymen-8-ol & 1871 & 1.54 \\
\hline 21 & & 1893 & 0.75 \\
\hline 22 & a-agarofuran & 1912 & 1.15 \\
\hline 23 & & 1971 & 0.83 \\
\hline 24 & caryophyllene oxide & 2017 & 0.87 \\
\hline 25 & & 2074 & 1.06 \\
\hline 26 & & 2087 & 1.53 \\
\hline 27 & a-cedrene & 2094 & 2.69 \\
\hline 28 & elemol & 2103 & 2.30 \\
\hline 29 & 10-eip-y-eudesmol & 2130 & 3.38 \\
\hline 30 & & 2151 & 1.09 \\
\hline 31 & a-eudesmol & 2170 & 3.32 \\
\hline 32 & & 2182 & 0.82 \\
\hline 33 & agaruspirol & 2207 & 17.55 \\
\hline 34 & bicyclo[4,4,0]dec-1-en,2-isopropyl-5-methyl-9-methylene & 2213 & 1.25 \\
\hline 35 & calarene & 2237 & 10.07 \\
\hline 36 & guaiazolene & 2245 & 2.10 \\
\hline 37 & & 2252 & 4.99 \\
\hline 38 & b-eudesmol & 2252 & 4.99 \\
\hline 39 & oxo-a-ylangene & 2287 & 2.41 \\
\hline 40 & & 2318 & 0.92 \\
\hline 41 & & 2328 & 1.02 \\
\hline 42 & cycloisolongifolene & 2359 & 2.20 \\
\hline 43 & caryophylla-3,8(13)-dien-5.beta.-ol & 2363 & 0.78 \\
\hline 44 & & 2372 & 0.97 \\
\hline 45 & 4-isopropyl-6-methyl-1,2,3,4-trtrahydronaphthalen-1-one & 2376 & 0.71 \\
\hline 46 & 5-HydroxyCalamenene & 2613 & 0.93 \\
\hline
\end{tabular}

Note: $\mathrm{KI}$ values (retention indices) are calculated from the retention times relative to those of the $\mathrm{C} 7-\mathrm{C} 30$ 


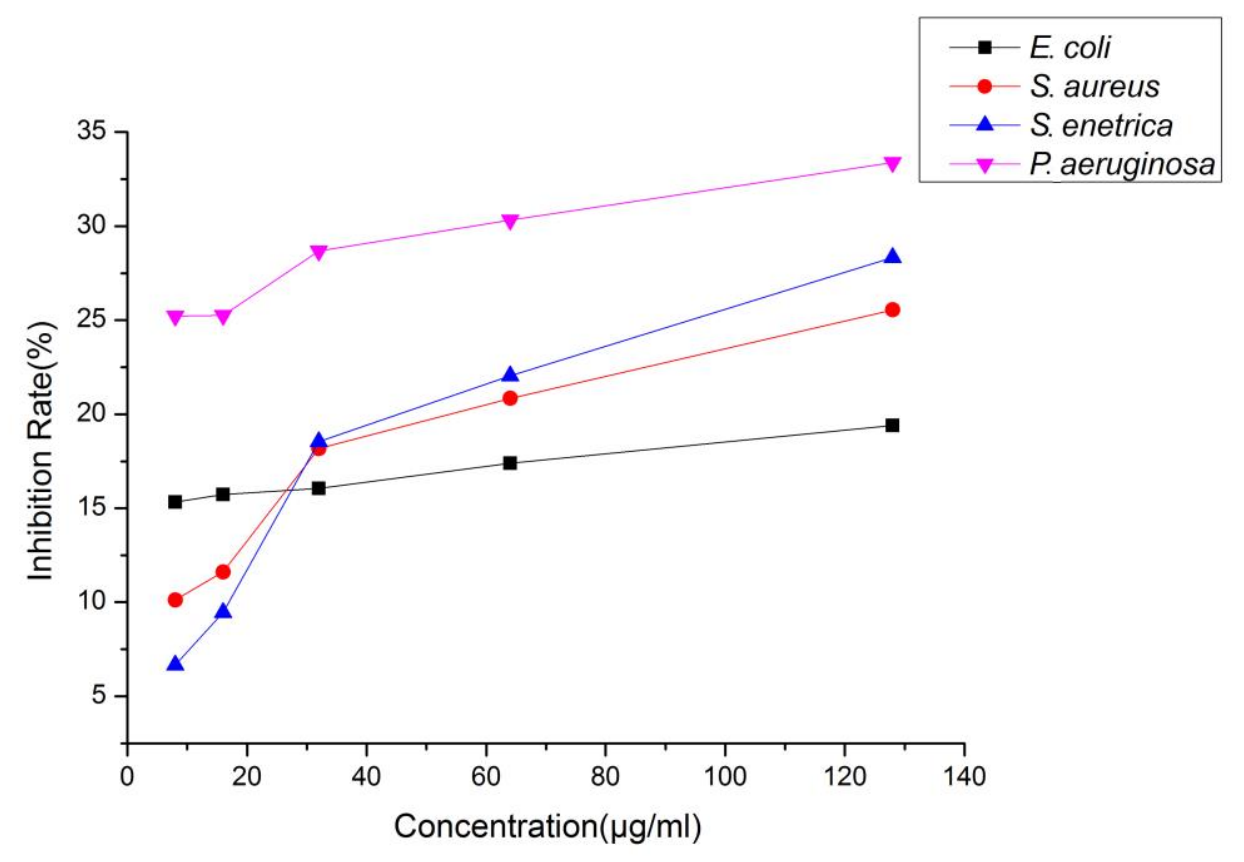

Fig. 1. Inhibition of four bacteria by different concentrations of the wood essential oil from P. bournei

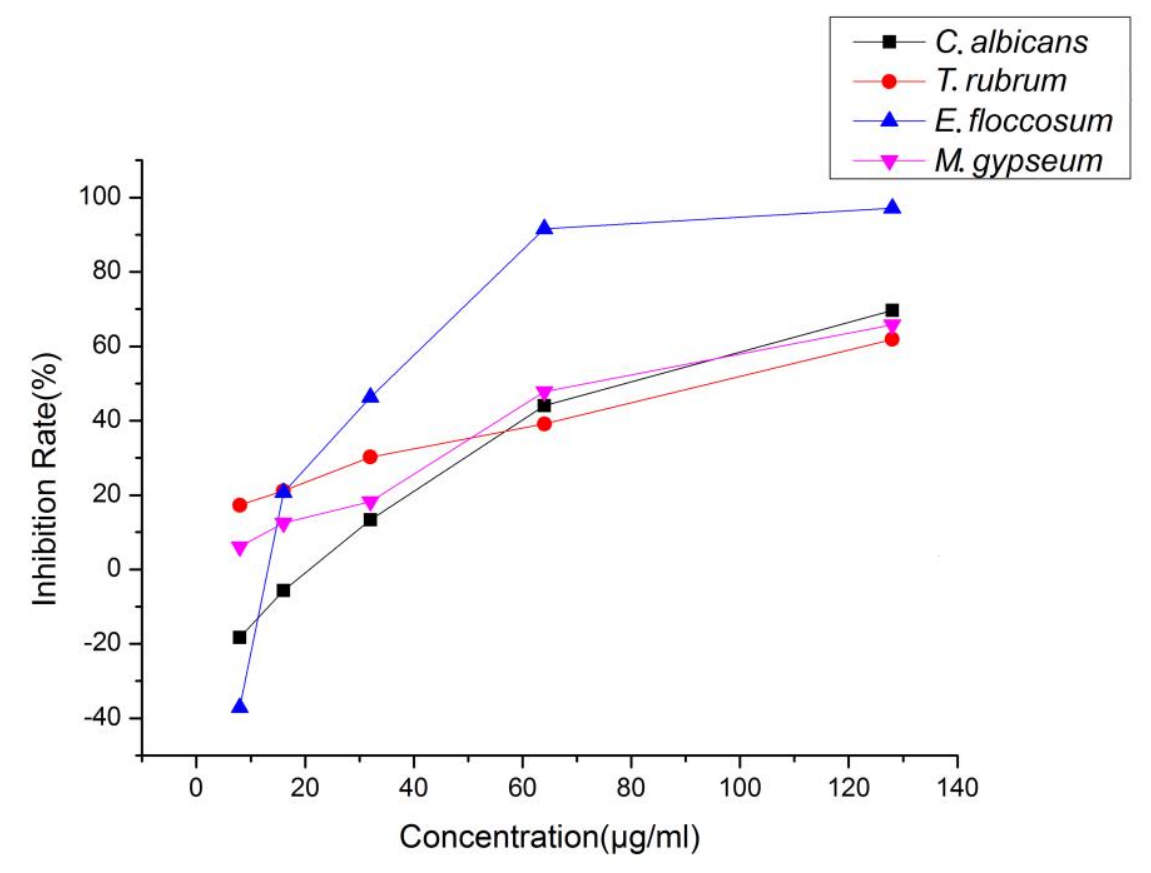

Fig. 2. Inhibition of four fungi by different concentrations of the wood essential oil from $P$. bournei Analysis of antifungal activities of the essential oil extracted from wood of P. bournei 
The positive drugs Amphotericin B and Terbinafine have an IC50 of less than $0.0125 \mu \mathrm{g} / \mathrm{mL}$ for the four fungi. Figure 2 shows that $E$. floccosum showed the most significant response to the change in wood essential oil concentration of $P$. bournei, and the inhibition rate varied significantly with the change in essential oil; different concentrations of $P$. bournei wood essential oil always inhibited the T. rubrum and $M$. gypseum. However, P. bournei wood essential oil demonstrated a promoting effect on $E$. floccosum and C. albicans at low concentrations: when the wood essential oil concentration was higher than $16 \mu \mathrm{g} / \mathrm{mL}$, the wood essential oil showed a certain degree of inhibition on the four test fungi, and in particular, the inhibitory effect on the E. floccosum was significantly better than that of the other three fungi. However, when the concentration was lower than $16 \mu \mathrm{g} / \mathrm{mL}$, the inhibitory effect on the E. floccosum and C. albicans was rapidly transformed into a significant promoting effect.

With the concentration of essential oil ranging from $8 \mu \mathrm{g} / \mathrm{mL}$ to $128 \mu \mathrm{g} / \mathrm{mL}$, the inhibitory rates of $P$. bournei wood essential oil on the four tested fungi showed an increasing trend. Wood essential oil exhibited significant inhibitory activity against Candida albicans ATCC10231, Trichophyton rubrum ATCC4438, Epidermophyton floccosum CBS566.94, and Microsporum gypseum CBS118893, with the $\mathrm{IC}_{50}$ values of 75 $\mu \mathrm{g} / \mathrm{mL}, 82.6 \mu \mathrm{g} / \mathrm{mL}, 33.6 \mu \mathrm{g} / \mathrm{mL}$, and $69.60 \mu \mathrm{g} / \mathrm{mL}$, respectively. Attention could be paid to the development of related antifungal active substances of $P$. bournei wood essential oil.

\section{Analysis of the antitumor effects of the essential oil extracted from wood of $P$. bournei}

Table 2 shows the results obtained from the in vitro comparison of the $\mathrm{IC}_{50}$ values of the samples. As shown, the essential oil from wood of P. bournei had good activity against leukemia cell lines, with an $\mathrm{IC}_{50}$ value of $42.7 \mu \mathrm{g} / \mathrm{mL}$. The essential oil from the wood of $P$. bournei exhibited poor activity against lung cancer, liver cancer, breast cancer, and colon cancer cell lines. In particular, the toxic activity of the lung cancer cells was the worst, with an $\mathrm{IC}_{50}$ values of more than $50 \mu \mathrm{g} / \mathrm{mL}$.

Table 2. Effect of the Essential Oil on the $\mathrm{IC}_{50}$ of Five Cancer Cells

\begin{tabular}{|c|c|c|c|c|c|}
\hline & $\begin{array}{c}\text { Leukemia } \\
\text { Cell Line HL- } \\
60\end{array}$ & $\begin{array}{c}\text { Lung Cancer } \\
\text { Cell Line } \\
\text { A549 }\end{array}$ & $\begin{array}{c}\text { Hepatoma Cell } \\
\text { Line SMMC-7721 }\end{array}$ & $\begin{array}{c}\text { Breast Cancer } \\
\text { Cell Line MCF- } \\
7\end{array}$ & $\begin{array}{c}\text { Colon } \\
\text { Carcinoma Cell } \\
\text { Line SW480 }\end{array}$ \\
\hline \multicolumn{5}{|c|}{ IC50 \pm SD $(\mu \mathrm{gg} / \mathrm{mL})$} \\
\hline Wood & $42.7 \pm 1.84$ & $>100$ & $88.1 \pm 2.79$ & $54.9 \pm 0.58$ & $75.6 \pm 2.10$ \\
\hline DDP & $2.3 \pm 0.81$ & $4.7 \pm 0.26$ & $6.9 \pm 0.59$ & $8.2 \pm 0.57$ & $8.1 \pm 1.44$ \\
\hline Taxol & $<0.0068$ & $<0.0068$ & $<0.0068$ & $<0.0068$ & $<0.0068$ \\
\hline
\end{tabular}

P. bournei wood essential oil exhibited good activity against leukemia cell lines, and exhibited the worst activity against lung cancer cell lines. This is the same as the results for Phoebe hui and Phoebe zhennan wood essential oil (Ding et al. 2017a,b). Further attention could be paid to the research and development of antitumor-related products.

Analysis of the hypoglycemic activity of the essential oil extracted from wood of P. bournei

Table 3 shows the effects of essential oil extracted from the wood of $P$. bournei on cell glucose uptake. In the adipocyte glucose uptake model, wood essential oil acted at a concentration of $40 \mu \mathrm{g} / \mathrm{mL}$ for $24 \mathrm{~h}$, and the adipocyte glucose consumption rate was increased. That is, wood essential oil played a certain role in the promotion of glucose uptake by adipocytes. It also showed a certain potential for hypoglycemic activity, although 
there was still a certain gap between the oil and the mature hypoglycemic drugs. Because essential oil is a mixture, the concentration of effective components within the volume was relatively low, and thus the wood essential oil of $P$. bournei was basically non-toxic to adipocytes at this concentration. Thus, there is still a certain potential for exploring its effects on hypoglycemic activity.

Table 3. Effects of $P$. bournei Wood Essential Oil on Glucose Consumption Rate

\begin{tabular}{|c|c|c|}
\hline Sample & Final Concentration & Glucose Consumption Rate (\%) \\
\hline DMSO (Control) & & $16.23 \pm 1.57$ \\
\hline Insulin & $0.1 \mu \mathrm{M}$ & $38.22 \pm 1.18$ \\
\hline Berberine $(235.324)$ & $10 \mu \mathrm{M}$ & $31.23 \pm 1.77$ \\
\hline Wood & $40 \mu \mathrm{g} / \mathrm{mL}$ & $20.49 \pm 1.35$ \\
\hline
\end{tabular}

\section{CONCLUSIONS}

1. The main components of Phoebe bourne $i$ wood essential oil are $\alpha$-copaene $(5.44 \%), \alpha$ muurolene $(7.32 \%), \delta$-cadinene $(11.44 \%)$, and 1s-calamenene $(5.18 \%)$. The composition of wood essential oil is different from that of Phoebe zhennan and Phoebe $h u i$, so it is feasible to use the chemical composition of $P$. bournei as a marker to identify $P$. bournei.

2. P. bournei wood essential oils exhibited some inhibitory effect on the eight tested bacteria and fungi relative to the control, and with the increase of essential oil concentration, the inhibition rate showed an increasing trend. The essential oil had weaker activity against Escherichia coli ATCC25922, Staphylococcus aureus subsp. aureus ATCC29213, Salmonella enterica subsp. enterica ATCC14028, and Pseudomonas aeruginosa ATCC27853. Among the four tested fungi, the wood essential oil of $P$. bournei had significant inhibitory activity against Candida albicans ATCC10231, Trichophyton rubrum ATCC4438, Epidermophyton floccosum CBS566.94, and Microsporum gypseum CBS118893.

3. P. bournei wood essential oil exhibited good activity against leukemia cell lines, and exhibited the worst activity against lung cancer cell line. P. bournei wood essential oil acted at a concentration of $40 \mu \mathrm{g} / \mathrm{mL}$ for $24 \mathrm{~h}$, which had a certain role in promoting glucose uptake by adipocytes.

\section{ACKNOWLEDGMENTS}

The authors are grateful for the support of Sichuan University. Thanks to Professor Ning. 


\section{REFERENCES CITED}

Bedini, S., Flamini, G., Cosci, F., Ascrizzi, R., Benelli, G., and Conti, B. (2016).

"Cannabis sativa and Humulus lupulus essential oils as novel control tools against the invasive mosquito Aedes albopictus and fresh water snail Physella acuta," Ind. Crop.

Prod. 85, 318-323. DOI: 10.1016/j.indcrop.2016.03.008

Chen, Y. X., and Xie, C. P. (2014). "Geographical distribution and resource protection countermeasures of Phoebe Ness from East China," J. Fore. Tech. Dvpt. 28(03), $13-$ 17. DOI: 10.13360/j.issn.1000-8101.2014.03.003

Ding, W., Ning, L. P., Wang, Y. G., Xiong, Y., Zhang, S., and Liu, J. (2017a). "Study on chemical compositions of phytoncidere and essential oil and bioactivity of essential oil from Phoebe zhennan," J. Northwest A. \& F. University 45(9), 123-128. DOI: 10.13207/j.cnki.jnwafu.2017.09.017

Ding, W., Ning, L. P., Xiong, Y., Shi, H., Wang, T. S., and An, R. M. (2017b). "Essential oil extracted from Phoebe hui Cheng ex Yang: Chemical constituents, antitumor and antibacterial activities, and potential use as a species identifier," J. Wood Chem. Tech. 37(3), 201-210. DOI: 10.1080/02773813.2016.1271435

Gao, J., Shang, H., Chen, Z., Tian, Y., and Yu, H. (2016). "Effects of elevated ozone on stoichiometry and nutrient pools of Phoebe bournei (Hemsl.) Yang and Phoebe zhennan S. Lee et F. N. Wei seedlings in subtropical China," Forests 7(78), 1-10. DOI: $10.3390 / \mathrm{f} 7040078$

He, Y. H., Liang, R. L., Jiang, Y., and Sun, B. (2013). "Research progress of precious species Phoebe bournei and its development strategies," Guangxi Fore. Sci. 42(4), 465-370. DOI: 10.19692/j.cnki.gfs.2013.04.015

Huang, Y., Li, J. M., Fan, H. H., Liu, B., and Yao, X. M. (2016). "Analysis of seedling growth difference and genetic variation of Phoebe bournei (Hemsl.) Yang in different seed collecting points," J. Fujian Fore. Sci. Tech. 43(1), 20-24. DOI: 10.13428/j.cnki.fjlk.2016.01.004

Huang, Y., Zhang, J., Lin, Z. Y., Chen, E., and Fan, H. H. (2017). "Analysis on young plantation growth of different specifications container seedlings afforestation in Phoebe bournei (Hemsl.) Yang," J. Fujian Fore. Sci. Tech. 44(4), 23-27. DOI: 10.13428/j.cnki.fjlk.2017.04.005

Jiang, X. M., Xiao, F. M., Gong, B., and Ye, J. S. (2008). "Study on physical and mechanical properties of Phoebe bournei wood from plantation and natural forest," Forest Research 21(6), 862-866. DOI: 10.13275/j.cnki.lykxyj.2008.06.024

Li, X. B., Yu, Z. X., Shao, T. M., Chen, G. Y., and Song, X. P. (2017). "Chemical composition and antitumor activities of Polyalthia consanguinea essential oil," Chinese Journal of ETMF 23(17), 58-62. DOI: 10.13422/j.cnki.syfjx.2017170058

Liu, B., Chen, C. J., Lin, D. D., and Lin, S. Z. (2014a). "Analyses of photosynthetic pigment content and chlorophyll fluorescence parameter in leaves of 21 provenances of Phoebe bournei," Acta Agri. Univ. Jiangxi. 36(1), 115-121. DOI: 10.13836/j.jjau.2014018

Liu, G., Tu, M., Li, F., and Fei, Y. J. (2014b). "Research on photosynthetic physiology of Phoebe bournei and Phoebe zhennan on saline stress," J. Huibei Fore. Sci. Tech. 43(6), 9-12, 20. DOI: 10.3969/j.issn.1004-3020.2014.06.003

Liu, X. R. (2003). "Study on antimicrobial action of the extraction mixture from garlic, 
ginger and tangerine peel," Guangzhou Food Sci. Tech. 19(1), 26-29. DOI:

10.13982/j.mfst.1673-9078.2003.01.011

NCCLS (2002a). "Reference method for broth dilution antifungal susceptibility testing of yeasts," National Committee for Clinical and Laboratory Standards, approved standard, 2nd Ed., NCCLS Document M 27-A2, vol. 22, No.15. NCCLS, Wayne, PA, pp. $1-29$.

NCCLS (2002b). "Reference method for broth dilution antifungal susceptibility testing of filamentous fungi," National Committee for Clinical and Laboratory Standards, approved standard, 2nd Ed., NCCLS Document M 38-A, vol. 22, No. 16. NCCLS, Wayne, PA, pp. 1-29.

NCCLS (2009). "Methods for Dilution antimicrobial susceptibility tests for bacteria that grow aerobically," National Committee for Clinical and Laboratory Standards, 2009, approved standard - 7th Ed., NCCLS Document M 07-A8, vol. 29, No. 2. NCCLS, Wayne, PA, pp. 1-65.

Perdones, Á., Escriche, I., Chiralt, A., and Vargas, M. (2016). "Effect of chitosan-lemon essential oil coatings on volatile profile of strawberries during storage," Food Chem. 197, 979-986. DOI: 10.1016/j.foodchem.2015.11.054

Ren, W. J., Wen, Z. M., Xiao, S. C., Wu, Y. Z., Chen, P. Q., and Luo, Q. R. (1990). "Studies on chemical components of the essential oil from the peel of Phoebe zhennan," Natural Prod. $R$ \& D 2(3), 59-62. DOI: 10.16333/j.1001-6880.1990.03.012

Salahfatnassi, K. B. H., Hassayoun, F., Cheraif, I., Khan, S., Jannet, H. B., and Hammami, M. (2016). "Chemical composition, antibacterial and antifungal activities of flowerhead and root essential oils of Santolina chamaecyparissus 1. growing wild in Tunisia," Saudi J. Biol. Sci. 24(4), 875. DOI: 10.1016/j.sjbs.2016.03.005

Shao, M. X., Wen, S. Z., He, G. X., Zhao, X. Z., and Ou, Y. Q. (2014). "The biomass structure characteristics of $P$. bournei (Hemsl.) Yang plantation in different ages," $J$. Central South Univ. Fore. Tech. 34(6), 44-48. DOI: 10.14067/j.cnki.1673923x.2014.06.017

Wang, D. G., Yin, G. T., Zou, W. T., Li, R. S., and Yang, J. C. (2013). "Effects of nitrogen loading on growth and photosynthetic characteristics of Phoebe bournei seedlings," Forest Research 26(1), 70-75. DOI: 10.13275/j.cnki.lykxyj.2013.01.015

Wang, T. S., Shi, H., Tao, X. Y., An, R. M., Xiong, Y., and Ning, L. P. (2017). "Chemical assistant identification of Phoebe zhennan by GC-MS," J. Northeast Forestry University 45(6), 57-60. DOI: 10.13759/j.cnki.dlxb.2017.06.012

Xue, X. M., and Zhao, Y. S. (2017) "Identification of two species of Dalbergia by Fourier transform infrared spectroscopy," J. Zhejiang Fore. Sci. Tech. 37(6), 63-68. DOI: 10.3969/j.issn.1001-3776.2017.06.011

Yang, J., Ning, L. P., Liu, M., Liu, H., Liao, X. L., and Hu, R. Z. (2018). "Wood characteristics and radial variations of Phoebe zhennan," J. Northwest A \& F Univ. 46(2), 7-14. DOI: 10.13207/j.cnki.jnwafu.2018.02.002

Yu, Y., and Chen, S. X. (2017). "Influence of different afforestation lands on the young growth of Phoebe bournei (Hemsl.) Yang," Hunan Fore. Sci. Tech. 44(4), 28-31. DOI: 10.3969/j.issn.1003-5710.2017.04.006

Zhang, L. B., and Iwatsuki, K. (2013). "Phoebe Nees, Syst. Laur.," in: Flora of China, Z. Y. Wu, P. H. Raven, and D. Y. Hong (eds.), Science Press, Beijing.

Zhang, L. J., Hu, W., Mo, M. X., Liang, Y. N., and Chen, S. L. (2016a). "Study on seedling breeding and afforestation technology of Phoebe bournei (Hemsl.) Yang," 
Central South Forest Inventory \& Planning 35(2), 41-44. DOI: 10.16166/j. cnki.cn43-1095.2016.02.009

Zhang, L., Zhang, Y., Duan, R. Y., Wei, X. L., and Xu, X. Q. (2016b). "Genetic variation among origin locations of Phoebe bournei (Hemsl.) Yang and a preliminary selection based on seedling growth and root traits," J. Nanjing Fore. Univ. 40(6), 33-40. DOI: 10.3969/j.issn.1000-2006.2016.06.006

Zhang, R., Zhou, Z., Jin, G., Wang, S., and Wang, X. (2012). "Genetic diversity and differentiation within three species of the family Lauraceae, in southeast China," Biochemical Systematics \& Ecology 44(10), 317-324. DOI: 10.1016/j.bse.2012.06.007

Zhang, Y. L., Zhang, R. G., and Zhong, Y. (2011). "Chemical component, antimicrobial effect, antioxidation activity and toxicological character of thyme essential oil," Scientia Agricultura Sinica 44(9), 1888-1897. DOI: 10.3864/j.issn.05781752.2011.09.016

Zhou, X. F., Niu, S. K., Song, X. Y., and Li, Y. Q. (2005). "Research on niche of Phoebe bournei (Hemsl.) Yang community in Fujian Luoboyan Nature Reserve," J. Sanming College 22(2), 175-177. DOI: 10.14098/j.cn35-1288/z.2005.02.013

Article submitted: September 7, 2018; Peer review completed: November 26, 2018;

Revisions accepted: December 1, 2018; Published: December 7, 2018.

DOI: 10.15376/biores.14.1. 858-869 